14

\title{
Формирование фотоакустического отклика в двуслойной структуре полимер/гель
}

\author{
(ㄱ Д.А. Андрусенко, А.Н. Алексеев, А.Г. Кузмич, М.М. Лазаренко, С.В. Василюк, Р.М. Бурбело \\ Киевский национальный университет им. Тараса Шевченко, \\ 01601 Киев, Украина \\ e-mail: and_@univ.kiev.ua
}

Поступило в Редакцию 25 июля 2020 г.

В окончательной редакции 20 августа 2020 г.

Принято к публикации 21 августа 2020 г.

Проведены экспериментальные исследования процессов формирования фотоакустического отклика от слоистой структуры полиэтилен/гидрогель при ее облучении периодически модулированным светом. Тепловые источники расположены в геле, вблизи границы раздела с полиэтиленом. Отклик в форме колебаний давления газа в фотоакустической ячейке возникает вследствие термоупругой деформации слоя полиэтилена при его неоднородном по толщине нагреве температурной волной. Полученные результаты могут быть полезными для модификации методов, основанных на процессах диффузии в гелях.

Ключевые слова: фотоакустический эффект, температурная волна, „drum effect,, модулированный свет, агароза, газомикрофонный метод, термоупругие деформации, диффузия, гидрогель.

DOI: $10.21883 /$ JTF.2021.02.50373.231-20

\section{Введение}

Актуальной задачей современной прикладной физики является поиск новых принципов и закономерностей, которые можно положить в основу создания и работы различных сенсорных устройств, в частности таких, как биосенсоры и системы „lab-on-chip“ $[1,2]$. В таких системах ключевым является выбор чувствительного слоя и физических механизмов, лежащих в основе формирования информативного сигнала. Одним из подходов к построению сенсорных структур является использование пористых материалов с большой удельной площадью поверхности [3]. Для биомедицинских приложений такая структура должна работать в водных растворах и, следовательно, требует гидрофильных свойств поверхности ее матрицы.

Широким классом биосовместимых пористых материалов с развитой сетчатой структурой являются гидрогели [4]. Ярким представителем этого класса материалов являются гели на основе агарозы. Агароза - линейный гидрофильный полисахарид, ее полимерные цепи в большей степени, чем целлюлоза способны образовывать водородные связи, в результате чего уже $1-5 \%$ водный раствор при застывании образует жесткий гель с крупными порами. Гели на основе агарозы являются удобными материалами при создании фантомных объектов с целью замены реальных образцов биологических тканей в процессе апробирования различных биофизических методов диагностики [5-7]. Кроме того, эти гели широко применяются в аналитических методах для разделения и идентификации крупных биологических молекул и наночастиц [8-10].

В последние годы широкую известность для приложений тераностики [11] приобрели фотоакустические (ФА) методы, в частности, ФА-томография биологических тканей, включая исследования in vivo на живых организмах [12,13]. Методы ФА-томографии используют возбуждение звука в результате поглощения излучения импульсного лазера и позволяют визуализировать в тканях неоднородности разной природы. При этом сложно получать количественные данные о параметрах материала образца. С другой стороны, классические методы ФА с газомикрофонной регистрацией сигнала и периодической модуляцией возбуждающего излучения позволяют производить бесконтактные измерения ряда упругих и теплофизических параметров [14-17]. Преимуществом этих методов является возможность зондирования по глубине тонких (до нескольких сотен $\mu \mathrm{m}$ ) приповерхностных слоев материалов простым изменением частоты модуляции возбуждающего термоупругие колебания излучения. Кроме того, методы классической ФА-спектроскопии могут быть использованы в сложных для других методов случаях: слабое и, напротив, очень сильное поглощение излучения; сильно рассеивающая свет среда. Важным здесь является методическая близость импульсных и газомикрофонных ФА методов, что в перспективе позволит объединить их преимущества в комплексных конструктивных решениях для систем сбора информации при диагностике патологий биологических тканей.

Для реализации описанных выше подходов необходимым является разработка новых способов формирования ФА-отклика. Это обусловлено тем, что классический вариант формирования информативного сигнала требует размещения исследуемого материала так, чтобы облучаемая возбуждающим излучением поверхность образца находилась в тепловом контакте с рабочим газом в 
герметически замкнутом малом объеме [18], что сложно реализовать при исследованиях in viva.

В настоящей работе для формирования ФА-отклика от мягких материалов предлагается модификация классического газомикрофонного метода. В этом варианте образец геля в виде пластины приводится в акустический и тепловой контакт с пластиной оптически прозрачного полимера (полиэтилена) с большим значением коэффициента теплового расширения. ФА-отклик формируется как результат термоупругой деформации полиэтилена. Соответственно целью настоящей работы является исследование физических закономерностей формирования ФА-сигнала в слоистой структуре полиэтилен/гель.

Подчеркнем, что важность данных исследований обусловлена необходимостью понимания процессов формирования ФА-отклика в слоистых структурах со слоями гелеобразных материалов как объектов близких по физическим свойствам к биологическим тканям, а также структур, перспективных для сенсорных и актуаторных устройств.

\section{1. ФА-метод открытого окна}

\section{1. Классический вариант}

Механизм формирования ФА-сигнала от образцов гидрогелей в экспериментах, выполненных в настоящей работе, сходен с тем, который имеет место в классическом варианте газомикрофонного ФА-метода „открытого окна“, (open window (OW)) [19-21].

Геометрия экспериментальной структуры в методе OW представлена на рис. 1,a. Для сравнения на рис. $1, b$ приведена геометрия, предложенная нами для исследования мягких материалов. Модулированный свет 2 поглощается на внешней (по отношению к рабочему объему ФА-ячейки) поверхности образца 1 с последующим выделением тепла. В классическом варианте образец непрозрачен, либо его поверхность покрывают тонким поглощающим свет слоем. К появлению ФА-отклика в виде колебаний давления газа 4 внутри ячейки 3 может привести два разных механизма. Во-первых, это теплоперенос через материал образца в направлении границы раздела с газом во внутреннем объеме ячейки. В результате вблизи этой поверхности происходит периодический нагрев газа, и возникают колебания давления внутри ячейки. Этот механизм формирования отклика принято называть термоволновым (иначе, механизм газового поршня [17]). Во-вторых, существует механизм, который называют термоупругим (иначе „drum effect $\left.{ }^{6}[18,19]\right)$. При этом колебания давления возникают как результат периодических изгибных деформаций образца вследствие его неоднородного по толщине нагрева. В полупериод роста температуры в образце изгиб приводит к увеличению внутреннего объем ячейки. Давление при этом падает. Полный ФА-сигнал формируется акустическим микрофоном 5 и пропорционален сумме изменений давления, вызванных каждым из

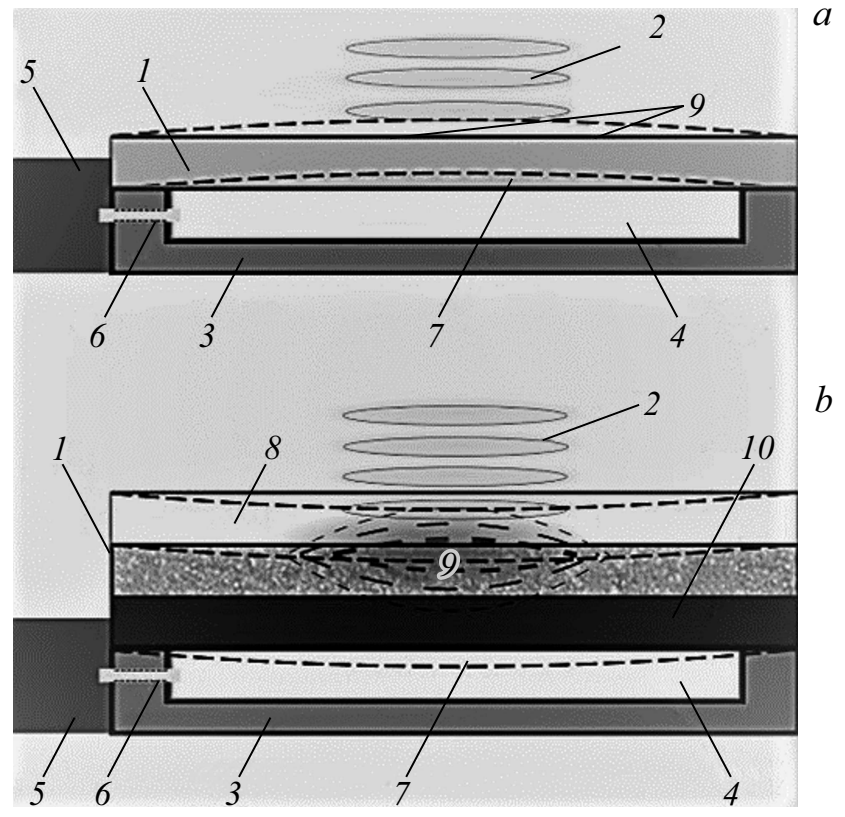

Рис. 1. Геометрия экспериментальной структуры для реализации ФА-метода „открытого окна“: $a-$ классический вариант, $b$ - вариант для получения ФА-отклика от мягких материалов. (1 - образец, 2 - модулированный свет, 3 - ФА-ячейка, 4 - рабочий газ, 5 - микрофон, 6 - соединительный канал, 7 - изменение объема ячейки вследствие изгиба образца, 8 - пластина полиэтилена, 9 - область выделения тепла, 10 - слой геля, насыщенный красителем до начала измерений). Показана фаза нагрева. Слой ПЭ выгибается в сторону нагретой поверхности. Механические параметры слоев 1 и 10 одинаковы.

механизмов по отдельности:

$$
P(t)=p_{g p}+p_{d},
$$

где $p_{g p}$ - компонента давления, связанная с колебаниями температуры обратной (по отношению к облучению) поверхности образца (термоволновой механизм, иначе механизм газового поршня), а $p_{d}-$ компонента, связанная с термоупругими деформациями образца (drum effect) [19].

$$
\begin{gathered}
p_{g p}=\frac{\gamma_{a} P_{0} I_{0}\left(D_{T g} D_{T s}\right)^{1 / 2}}{2 \pi l T_{0} \chi_{s} f} \cdot \frac{e^{-j \pi / 2}}{\operatorname{sh}\left(\sigma_{s} h\right)}, \\
p_{d}=\frac{3 \alpha_{T} r^{2}}{h^{2}} \cdot \frac{\gamma_{a} P_{0} I_{0}}{l \chi_{s} \sigma_{s}^{2}} \cdot\left(\frac{\operatorname{ch}\left(\sigma_{s} h\right)-1}{\sigma_{s} h \operatorname{sh}\left(\sigma_{s} h\right)}-1 / 2\right),
\end{gathered}
$$

где $D_{T s}$ и $D_{t g}$ - температуропроводности образца и воздуха соответственно, $\gamma_{a}$ - адиабатическая газовая постоянная, $T_{0}$ и $P_{0}-$ нормальные температура и давление, $I_{0}-$ интенсивность света, $\sigma_{g}=(j+1) / \mu_{g}$, $\mu_{g}=\sqrt{\chi_{s} / \pi c \rho f}-$ длина тепловой диффузии в образце, $\chi_{s}, \rho$ и $c$ - теплопроводность, плотность и теплоемкость образца, $r, l$ - внутренний радиус и толщина ФА-ячейки, $h$ - толщина образца, $f$ - частота модуляции. 
Таким образом, газ в методе открытого окна, как и в других газомикрофонных методах, выполняет роль как рабочего тела (тепловое расширение), так и среды для передачи звуковых колебаний к сенсору давления (микрофону). В известных реализациях метода открытого окна для формирования информативного отклика используют термоволновой механизм, а термоупругий минимизируют, например, путем демпфирования образца сравнительно толстым жестким прозрачным буфером. В далее описанных экспериментах с образцами гидрогелей, напротив, как основной был использован термоупругий механизм, а термоволновой минимизировали.

\section{2. Модификация метода для исследования гидрогелей}

Одна из основных задач, которая была решена в рамках настоящей работы - получение от образцов гидрогелей ФА-сигнала с достаточной для надежной регистрации амплитудой. Термоупругие напряжения, которые возникают в гидрогелях при неоднородном нагреве, малы по сравнению с напряжениями в твердых телах. Причина - малые значения упругих модулей (Юнга и сдвига), которые определяют величину изгибных деформаций, вследствие чего ФА-сигнал от пластины гидрогеля в традиционной геометрии открытого окна, описанной выше, мал настолько, что практически недоступен для регистрации. Поэтому в экспериментальную структуру был введен дополнительный слой в виде пластины, вырезанной из полиэтилена.

Выбор полиэтилена (ПЭВД - полиэтилен высокого давления, иначе LDPE) как рабочего тела в ФА-эксперименте обусловлен тем, что этот материал оптически прозрачен, имеет одно из наибольших для твердых тел значение коэффициента теплового расширения, а значения его модулей Юнга и сдвига хотя и меньше, чем у большинства твердых материалов, но все же на порядки превышают таковые для гидрогелей.

Геометрия ФА-эксперимента приведена на рис. $1, b$. Модулированное по амплитуде (прерывание со скважностью 2) оптическое излучение 2 направляли на образец 1 со стороны ПЭ слоя 8 . Излучение проходит сквозь полиэтилен и частично поглощается в геле. Тепло выделяется в области 9 внутри геля. Часть этого тепла из области вблизи границы раздела ПЭ/гель на расстоянии меньше трех длин тепловой диффузии вследствие теплопередачи (температурная волна) попадает в пластину ПЭ, где $\mu_{s}$ становится причиной ее термоупругого изгиба. Изгиб полиэтилена влечет за собой и изгиб образца. При периодической во времени изгибной деформации образца возникают периодические колебания давления в ФА-ячейке, которые и регистрируются акустическим микрофоном.

Определяющими процессами при формировании сигнала в описанной выше геометрии эксперимента, как и в классических ФА-методах, являются процессы поглощения излучения в образце и тепловой транспорт в нем (передача тепла в ПЭ, тогда как в классическом варианте - в газ). Поэтому параметры ФА-сигнала должны зависеть от коэффициента поглощения излучения в геле и от его теплофизических свойств, в частности, от теплоемкости и теплопроводности. Следовательно, предложенная геометрия эксперимента может быть использована для спектроскопических и калориметрических исследований мягких материалов.

Открытыми остаются вопросы оптимизации геометрии структуры и влияния механических свойств слоя геля на параметры сигнала. Так, очевидно, что при частотах модуляции света, близких к частотам механического резонанса, существенным становится влияние инерционных свойств образца (масса) и влияние процессов диссипации энергии колебаний в нем (внутреннее трение). Эти вопросы трудно решить путем моделирования, поскольку математическое описание термоупругой деформации слоистых структур с сильным отличием значений упругих модулей не может быть выполнено в рамках обычного подхода жестких нормалей $[16,22]$. Предварительный анализ далее проведен на основе экспериментальных исследований, выполненных на простых модельных структурах.

\section{2. Объекты и эксперимент}

Для выяснения основных закономерностей формирования ФА-отклика от двуслойной структуры ПЭ-гель, частотные зависимости параметров ФА-сигналов, полученных от структур указанного типа, сравнивали с соответствующими зависимостями для сигналов от однородных пластин ПЭ. Анализировали две принципиально отличные между собой предельные экспериментальные ситуации: с локализацией источников тепла вблизи фронтальной (внешней по отношению к ФА-ячейке), либо тыльной поверхности пленки ПЭ (рис. 2). Для простоты выбран случай сильного поглощения излучения, который реализовывали нанесением на одну из поверхностей полиэтиленовой пластины тонкого слоя пигмента черного маркера.

- Вариант 1. Образец - пластина полиэтилена; источник тепла находится на: а) обратной стороне ПЭ пластины (рис. 2,a), б) источник тепла на фронтальной поверхности (рис. 2,b).

- Вариант 2. Образец - двуслойная структура ПЭ-гель: в) источник тепла на границе раздела ПЭ/гель (рис. 2,c), г) сточник тепла на внешней (фронтальной) поверхности структуры (рис. $2, d$ ).

Рабочий объем ФА-ячейки, заполненный воздухом при атмосферном давлении, имел форму диска с диаметром $8 \mathrm{~mm}$ и толщиной $1 \mathrm{~mm}$. Длина соединительного канала для связи рабочего объема ячейки с микрофоном составляла $12 \mathrm{~mm}$ при диаметре около $1.5 \mathrm{~mm}$. Возбуждение изгибных термоупругих квазистатических колебаний пластины ПЭ осуществляли путем ее нагрева модулированным светом зеленого светодиода (длина 

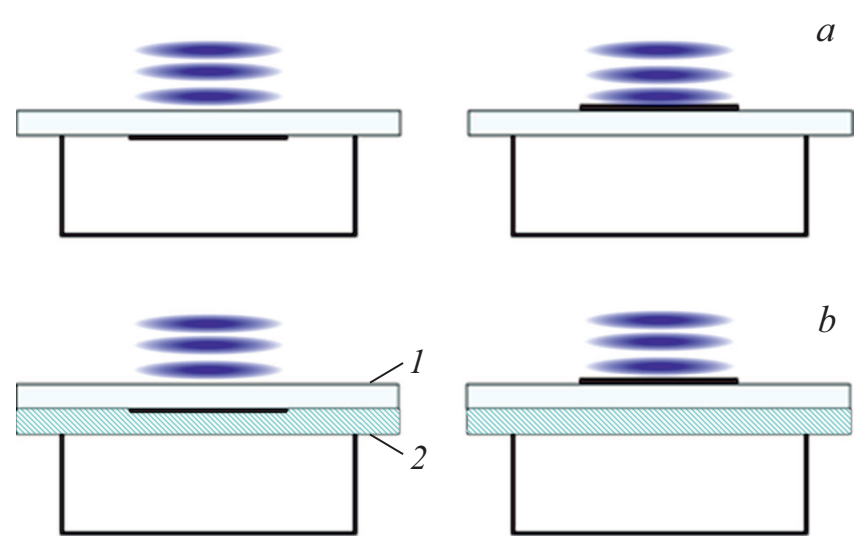

Рис. 2. Геометрия эксперимента: $a-$ образец - пластина ПЭ (1) со слоем пигмента на тыльной (внутренней по отношению к ФА-ячейке) поверхности; $b$ - тоже, слой пигмента на фронтальной поверхности; $c, d-$ тоже, со слоем гидрогеля агарозы (2) на тыльной поверхности пластины ПЭ.

волны $530 \mathrm{~nm}$, электрическая мощность $3 \mathrm{~W}$ ), мощность собранного на поверхности образца в пятно диаметром примерн $4 \mathrm{~mm}$ излучения по амплитуде составляла $(20 \pm 5) \mathrm{mW}$. Модуляцию света осуществляли прерыванием питающего светодиод тока со скважностью 2. Сигнал формировался электретным микрофоном с чувствительностью $1 \mathrm{~V} / \mathrm{Pa}$. Измерения амплитуды и фазового сдвига сигнала проводили синхронным нановольтметром UNIPAN-232B.

Слои 1.7\% гидрогеля агарозы (Sigma-Aldrich Agarose For Routine) толщиной $1.2 \mathrm{~mm}$ получали путем заполнения раствором агарозы в воде при температуре около $80^{\circ} \mathrm{C}$ зазора между двумя стеклянными пластинами. Двухслойные структуры ПЭ/гель изготовляли простым наложением слоя геля на пластины ПЭ. При этом сцепление слоев на границе ПЭ/гель обеспечивается смачиванием ПЭ водой. Пластины ПЭ (ООО „Завод полимерных материалов “Союз“ г. Киев.) имели толщину из набора 50, 105, 140, 160 и $170 \mu \mathrm{m}$.

\section{3. Результаты и обсуждение}

\section{1. ФА-эффект в полиэтилене}

Формирование сигнала в данном варианте может быть корректно описано в рамках классической модели (выражения (1) и (2)). Для нас тут будут важны лишь отдельные особенности, в частности, связанные с количественным соотношением вкладов термоупругой и термоволновой компонент отклика в ПЭ.

На рис. 3 приведены экспериментальные частотные зависимости отношения амплитуд при фронтальном $\left(A_{F}\right)$ и тыльном $\left(A_{R}\right)$ расположении пигмента на ПЭ пластинах разной толщины. Амплитуда регистрируемого сигнала на частотах, близких к $10 \mathrm{~Hz}$, составляла несколько десятков милливольт, что более чем достаточно для надежных измерений с отношением сигнал/шум не хуже $\sim 10^{3}$.

\section{Отметим следующее:}

Во-первых, фазы сигналов при расположении поглотителя на одной и той же стороне разных пластин (фронтальной либо тыльной) отличались между собой на каждой из частот на величину меньше $20^{\circ}$. При расположении же пигмента на разноименных поверхностях пластин одинаковой толщины фазовый сдвиг был близок к $180^{\circ}$.

Во-вторых, как видно из рис. 3, амплитуда ФА-сигнала всегда больше, когда тепловыделение происходит на тыльной (внутренней по отношению к ФА-ячейке) поверхности пластины. Так, для образца толщиной $170 \mu \mathrm{m}$ амплитуда сигнала при тыльном расположении пигмента превышает амплитуду сигнала при фронтальном расположении больше чем вдвое. Максимальное отношения амплитуды сигнала при фронтальном расположении пигмента к сигналу при тыльном его расположении наблюдали для образца толщиной $140 \mu \mathrm{m}$.

Длина тепловой диффузии в полиэтилене при частоте модуляции $100 \mathrm{~Hz}$ составляет $18 \mu \mathrm{m}$ [23] и с ростом частоты убывает обратно пропорционально ее квадратному корню. Поэтому в большей части исследованного диапазона частот образцы термически толстые $\left(\mu_{s} \gg h\right)$, и температурные волны не доходят до границы с газом. Фазовый сдвиг между термоволновой и термоупругой компонентами сигнала при тыльном расположении пигмента мал. Это понятно, поскольку квазистатическая деформация термически толстого образца происходит синфазно усредненной по тепловой волне неравновесной температуре его приповерхностной области. То же самое имеет место и для механизма „газового поршня“ с усреднением температуры по тепловой волне в газе; причем оба температурных поля имеют на границе раздела одинаковые амплитуды и фазы. Поэтому можно считать, что амплитуды обоих компонент складываются:

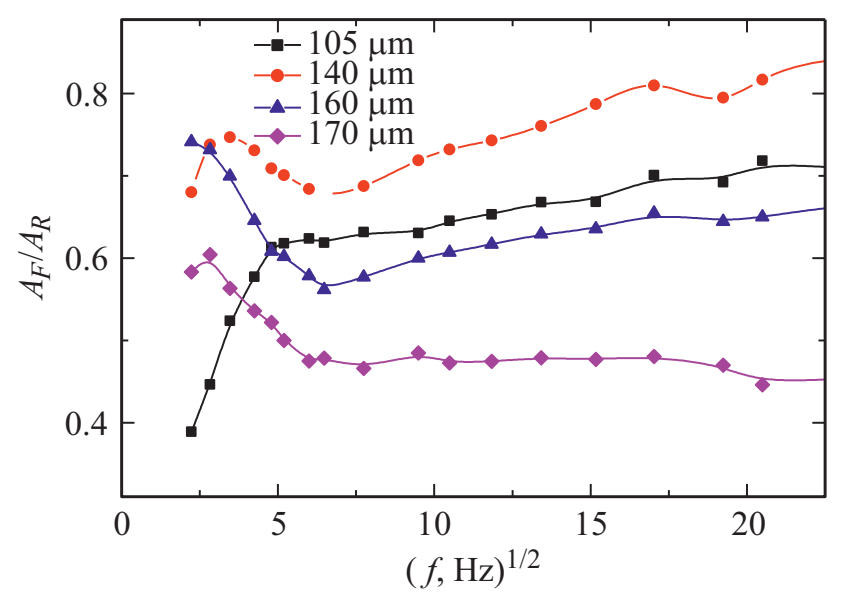

Рис. 3. Зависимость отношения амплитуд ФА-сигнала при фронтальном и при тыльном расположении области поглощения от квадратного корня частоты на пластинах ПЭ разной толщины. 
$A_{R} \sim\left(p_{g p}+p_{d}\right)$. При фронтальном расположении пигмента на частотах выше $40 \mathrm{~Hz}$, где образец термически толстый, ФА-отклик имеет чисто термоупругую природу $\left(A_{F} \sim p_{d}\right)$. Считая, что величина изгиба пластины не зависит от того, на какую из ее поверхностей нанесен пигмент (от этого зависит только направление прогиба, а значит, и знак изменения объема), можно сделать вывод, что при тыльном расположении пигмента амплитуды обеих компонент отклика соизмеримы. Более того, для образцов тоныше $170 \mu \mathrm{m}$ термоупругая компонента преобладала $p_{d} /\left(p_{g p}+p_{d}\right)>1 / 2$, откуда $p_{d} / p_{g p}>1$.

Не вдаваясь в подробности, отметим, что особенности зависимостей, приведенных на рис. 3, в области низких частот на качественном уровне могут быть полностью объяснены тем, что термоволновая компонента давления в отличие от термоупругой быстро меняется с частотой как по амплитуде, так и по фазе. Сильное изменение наклона зависимостей вблизи $f^{1 / 2} \approx 7$ имеет место для всех образцов вне зависимости от их толщины. Это изменение происходит, когда длина тепловой волны близка к толщине слоя газа в ячейке. На меньших частотах колебания температуры достигают тыльной стенки ФА-ячейки, и часть тепла передается в нее и, следовательно, не вызывает увеличения давления газа.

Таким образом, ФА-измерения, выполненные с образцами ПЭ, показывают, что в методе открытого окна при достаточной величине коэффициента теплового расширения образца термоупругая компонента может превышать по амплитуде составляющую, связанную с нагревом газа.

\section{2. ФА-эфффект в структуре ПЭ/гель}

Измерения выполнялись с использованием двуслойных экспериментальных структур ПЭ/гель, схематически изображенных на рис. 2,c,d при расположении поглощающего слоя поочередно на фронтальной $(d)$ и на тыльной $(c)$, граничащей с гелем, поверхностях ПЭ пленки. Слой геля везде имел толщину $h=1.2 \mathrm{~mm}$.

Частотные зависимости отношений амплитуд ФА-откликов от двуслойных структур $\left(A_{2 F}, A_{2 R}\right)$ к соответствующим амплитудам от однослойных пластин ПЭ $\left(A_{F}, A_{T}\right)$ приведены на рис. 4. Как видно из результатов эксперимента, в области низких частот модуляции присутствие геля всегда уменьшает амплитуду сигнала. При меньших толщинах пленки ПЭ ослабление ФА-сигнала гелем увеличивается. Для ПЭ пленки толщиной $160 \mu \mathrm{m}$ в области низких частот модуляции света влияние геля на амплитуду ФА-сигнала минимально. На сравнительно высоких частотах модуляции тут наблюдалось даже превышение амплитуды сигнала от двуслойной структуры по сравнению с ФА-сигналом от свободной ПЭ пленки. Вероятно, это связано с тем, что гель увеличивает общую массу структуры, уменьшая резонансную частоту системы, а наблюдаемое увеличение отклика обусловлено близостью резонансной частоты.
При сравнении между собой ФА-откликов от структур ПЭ/гель при локализации области поглощения излучения поочередно на фронтальной и на тыльной (граница раздела с гелем) поверхностях ПЭ пленки видно (рис. 4), что во втором случае наличие слоя геля приводит к более сильному уменьшению амплитуды сигнала. Это и понятно, поскольку при локализации области нагрева на границе раздела ПЭ/гель:

- во-первых, периодический нагрев воздуха внутри ФА-ячейки полностью отсутствует $\left(\mu_{s} \ll h\right)$, т. е. наблюдаем „выключение“ термоволнового механизма;

- во-вторых, происходит перераспределение потока тепла между ПЭ и гелем, что уменьшает термоупругие напряжения в ПЭ и изгиб структуры.

Из сопоставления данных экспериментов, представленные на рис. 3 и 4, можно сделать вывод, что оптимальными для получения максимальной амплитуды ФА-сигнала являются толщины ПЭ в диапазоне $100-160 \mu \mathrm{m}$. При уменьшении толщины ПЭ ниже этих значений велико гашение вынужденных колебаний структуры слоем геля. При увеличении же толщины ПЭ изгиб структуры и амплитуда сигнала уменьшается из-за малости доли прогретого слоя ПЭ по сравнению с полной толщиной пластины.

\section{3. ФА-исследования диффузии красителя в гидрогеле агарозы}

Ниже приведены результаты, иллюстрирующие одно из возможных применений рассмотренного выше способа формирования ФА-сигнала - изучение кинетики диффузионных процессов в тонких слоях мягких материалов в нормальном к поверхности слоя направлении.

Геометрия эксперимента соответствует представленной на рис. $1, b$.

Готовились два образца агарового геля концентрации $1.7 \%$ с толщиной $1.2 \mathrm{~mm}$. Перед началом измерений один из образцов погружали на $48 \mathrm{~h}$ в $1 \%$ водный раствор родамина G. Второй образец в течение того же времени находился в дистиллированной воде.

Исходная оптическая плотность слоя с красителем такова, что свет практически не проходит сквозь этот слой и полностью поглощается в нем. Измерение выполнялось при частоте модуляции $18 \mathrm{~Hz}$. Длина тепловой диффузии в геле на этой частоте близка к $100 \mu \mathrm{m}$. Результаты измерений зависимости амплитуды ФА-отклика от времени с момента соприкосновения двух слоев геля, один из которых содержал краситель, представлены на рис. 5.

В начальный момент времени сразу после соединения между собой слоев структуры ФА-сигнал мал - тепловое расширение геля не приводит к формированию ФА-сигнала с амплитудой, достаточной для регистрации. Сигнал появляется после того, как краситель достигает слоев геля, расстояние от которых до границы раздела с пластиной ПЭ не превышает трех длин тепловой диффузии. Из этих слоев периодический поток тепла 

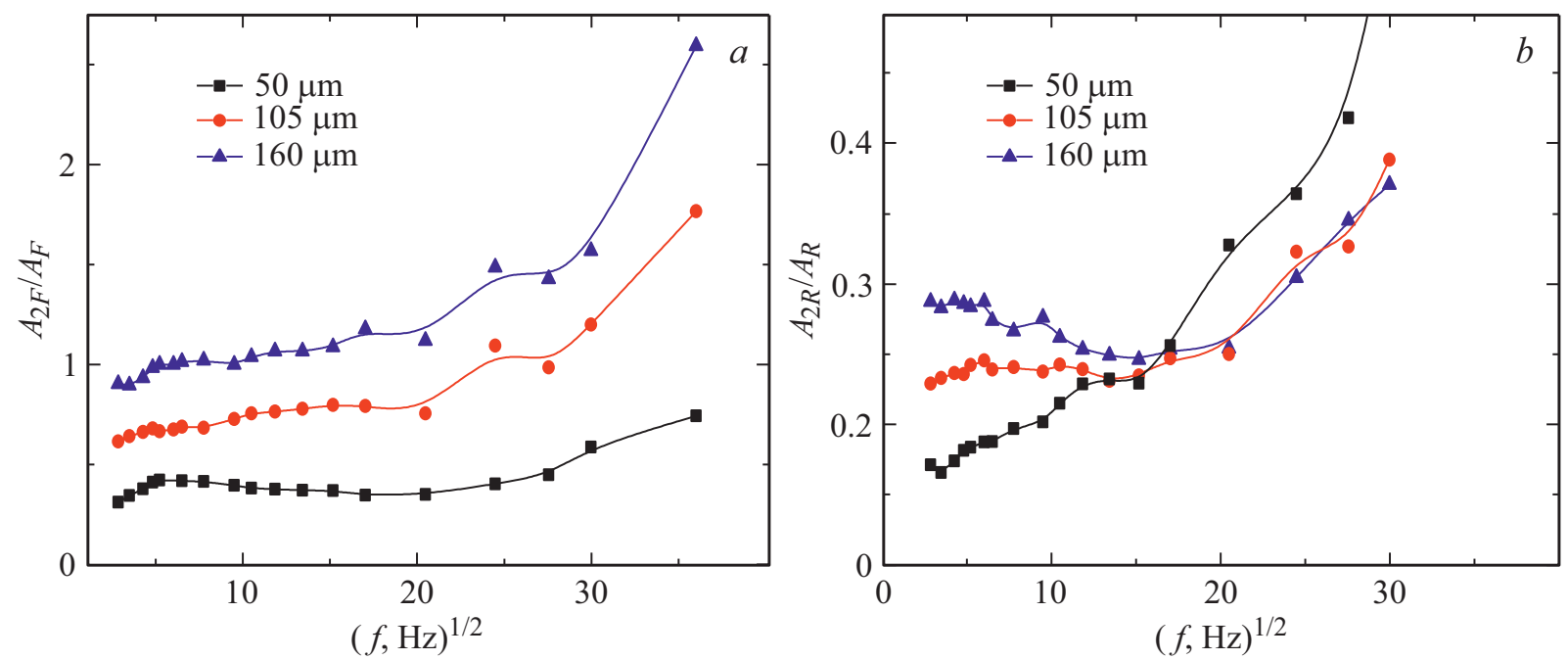

Рис. 4. Зависимость отношения амплитуд ФА-сигнала от структуры ПЭ/гель к сигналу от свободной ПЭ пластины при толщине ПЭ 50, 105 и $160 \mu \mathrm{m} . a-$ при фронтальном (рис. 2, $b, d ; b-$ при тыльном (рис. 2, $a, c$ ) расположении пигмента.

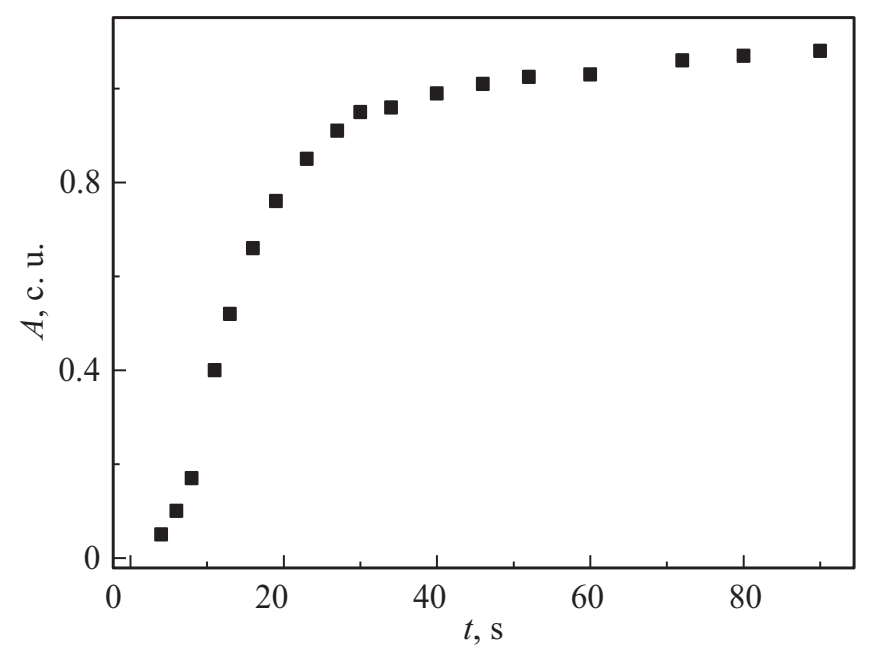

Рис. 5. Зависимость от времени амплитуды ФА-отклика в процессе диффузии красителя сквозь образец агарозного гидрогеля.

достигает ПЭ, где и формирует ФА-отклик. Рост амплитуды ФА-сигнала обусловлен нарастанием со временем концентрации красителя в геле вблизи границы раздела с ПЭ. Значительное уменьшение скорости роста амплитуды ФА-сигнала примерно через 20-25 s от начала эксперимента, по-видимому, обусловлено известным для газомикрофонных ФА-методов эффектом ФА-насыщения [18]. Это происходит, когда характерная длина поглощения света сравнивается, а затем становится меньшей, чем длина тепловой диффузии.

Возможно, при проведении описанного эксперимента имели место и процессы фотодеградации красителя [24]. Однако их вклад сравнительно мал, поскольку, преимущественно, такие процессы приводят к образованию неокрашенных компонент, что должно ослаблять
ФА-отклик, тогда как наблюдается его значительный рост с течением времени. К тому же эксперименты, в которых ранее наблюдали процессы фотодеструкции родамина, проводили с существенно большими интенсивностями света, спектр которого, кроме прочего, включал ультрафиолет. Вместе с тем следует подчеркнуть, что описанный метод может быть использован и для решения задач исследования кинетики химических и подобных реакций.

Таким образом, описанная методика, обладает чувствительностью к изменениям концентрации поглощающего свет компонента при его диффузии в направлении, нормальном к поверхности образца. Толщина слоя, с которого снимается информация, имеет порядок $100 \mu \mathrm{m}$ и может быть уменьшена до десятков $\mu \mathrm{m}$ путем увеличения частоты модуляции.

\section{Заключение}

В работе приведены результаты исследований формирования ФА-отклика от мягких материалов за счет термоупругой деформации дополнительного прозрачного полимерного слоя, приведенного в тепловой контакт с образцом и расположенного со стороны падения на образец возбуждающего излучения. Полученные результаты сравнивались с ФА-откликом от образца в виде однородной пластины полиэтилена.

Показано, что основным механизмом формирования ФА-отклика от двуслойных структур ПЭ/гель является изменение давления газа внутри ФА-ячейки в результате термоупругого изгиба пленки ПЭ. Деформация ПЭ приводит к изгибу слоя геля, причем этот изгиб даже при соотношении толщин ПЭ пластины и слоя геля $\sim 1: 10$ практически повторяет первичный изгиб, обусловленный термоупругой деформацией полиэтилена, с незначительным ослаблением. При уменьшении относительной 
толщины ПЭ в структуре ослабление ФА-отклика гелем возрастет. Оптимальными для получения максимальной амплитуды ФА-отклика являются толщины слоя ПЭ, близкие к $150 \mu \mathrm{m}$.

Продемонстрирована возможность использования предложенного способа формирования ФА-отклика для изучения кинетики диффузионных процессов в мягких материалах, в том числе в таких, где имеет место сильное рассеяние света. Преимуществом здесь является малая толщина образца, а следовательно, и существенное уменьшение времени эксперимента. Это особенно привлекательно для изучения процессов диффузии крупных биологических молекул и наночастиц, когда коэффициенты диффузии малы.

Приведенные данные могут стать основой для разработки модификаций многочисленных методов, которые основаны на процессах диффузии в гелях крупных органических молекул и в настоящее время широко применяются в биологических исследованиях.

\section{Конфликт интересов}

Авторы заявляют, что у них нет конфликта интересов.

\section{Список литературы}

[1] V.C. Romao, S.A. Martins, J. Germano, F.A. Cardoso, S. Cardoso, P. P. Freitas. ACS Nano, 11 (11), 10659 (2017). DOI: $10.1021 /$ acsnano.7b06703

[2] Е.А. Тутов. ЖТФ, 82 (6), 30 (2012). [E.A. Tutov. Tech. Phys., 57, 765 (2012). DOI: 10.1134/S1063784212060242]

[3] S. Behera, P.A. Mahanwar. Polymer-Plastics Technology and Materials, 59 (4), 341 (2020). DOI: $10.1080 / 25740881.2019 .1647239$

[4] N.A. Peppas, A.S. Hoffman. Hydrogels. In Biomaterials Science (Academic Press, 2020). DOI: 10.1016/B978-0-12-816137-1.00014-3

[5] B.W. Pogue, M.S. Patterson. J. Biomed. Opt., 11, 041102 (2006). DOI: $10.1117 / 1.2335429$

[6] W.C. Vogt, C. Jia, K.A. Wear, B.S. Garra, J. Pfefer. J. Biomed. Opt., 21, 101405 (2016). DOI: 10.1117/1.JBO.21.10.101405

[7] H.M. Heres, M.U. Arabul, M.C.M. Rutten, F.N. Van de Vosse, R.G.P. Lopata. J. Biomed. Opt., 22 (4), 041013 (2017). DOI: $10.1117 / 1 . J B O .22 .4 .041013$

[8] Е.С. Насонова. Цитология, 50 (11), 927 (2008).

[9] P.H. Johnson, L.I. Grossman. Biochemistry, 16, 4217 (1977) DOI: $10.1021 / \mathrm{bi00638a014}$

[10] M. Hanauer, S. Pierrat, I. Zins, A. Lotz, C. Sönnichsen. Nano Lett., 7, 2881 (2007). DOI: 10.1021/n1071615y

[11] Y. Liu, J.J. Yin, Z.H. Nie. Nano Res., 7, 1719 (2014). DOI: $10.1007 / \mathrm{s} 12274-014-0541-9$

[12] L.V. Wang, S. Hu. Science, 335, 1458 (2012). DOI: $10.1126 /$ science. 1216210

[13] L.V. Wang. Med. Phys., 35 (12), 5758 (2008). DOI: $10.1118 / 1.3013698$

[14] A.C. Tam. Rev. Mod. Phys., 58 (2), 381 (1986). DOI: $10.1103 /$ RevModPhys.58.381

[15] M.J. Adams, G.F. Kirkbright. Analyst., 102 (1213), 281 (1977). DOI: 10.1039/AN9770200281
[16] Д.А. Андрусенко, И.Я. Кучеров. ЖТФ, 69 (12), 1 (1999). [D.A. Andrusenko, I.Y. Kucherov. Tech. Phys. 44 (12), 1397 (1999). DOI:10.1134/1.1259558]

[17] U. Zammit, F. Mercuri, S. Paoloni, M. Marinelli, R. Pizzoferrato. J. Appl. Phys., 117, 105104, (2015). DOI: $10.1063 / 1.4914491$

[18] A. Rosencwaig, A. Gersho. J. Appl. Phys., 47 (1), 64 (1976). DOI: $10.1063 / 1.322296$

[19] L.F. Perondi, L.C.M. Miranda. J. Appl. Phys., 62 (7), 2955 (1987). DOI: $10.1063 / 1.339380$

[20] P. Charpentier, F. Lepoutre, L. Bertrand. J. Appl. Phys., 53 (1), 608 (1982). DOI: 10.1063/1.329966

[21] A. Somer, A. Gonçalves, T.V. Moreno, G.K. Cruz, M.L. Baesso, N. Astrath, A. Novatski. Meas. Sci. Technol., 31 (7), 075202 (2020). DOI: 10.1088/1361-6501/ab786a

[22] E.M. Zveriaev. Constructive theory of thin elastic shell (Preprints of the Keldysh Institute of Applied Mathematics, 2016). DOI: $10.20948 /$ prepr-2016-33

[23] A. Rosencwaig. Photoacoustics and Photoacoustic Spectroscopy (Wiley, GB, 1980). DOI: 10.1002/ange.19820940341

[24] Л.Ю. Садовская, Т.В. Свиридова, Т.М. Якименко, Д.В. Свиридов. Докл. НАН Беларуси, 60 (2), 58 (2016). 